\title{
Optimization of Cutting Parameters for Various Work-Tool Combinations in Turning Operation: An Experimental Investigation
}

\author{
G. Bharath Reddy ${ }^{1}$ and G. Naveen Kumar ${ }^{2}$ \\ ${ }^{1}$ Asst. Professor, CVR College of Engineering/Mechanical Department, Hyderabad, India \\ Email: gbharathreddys@gmail.com \\ ${ }^{2}$ Assoc. Professor, CVR College of Engineering/Mechanical Department, Hyderabad, India \\ Email: gnkumarmtech@gmail.com
}

\begin{abstract}
In the present research work the output responses Material Removal Rate (MRR) and Surface Roughness (SR) are studied and analyzed by varying the turning parameters like cutting speed, feed and depth of cut. The conventional turning of Stainless steel, Normalized steel and Aluminium work materials is carried out by using different cutting tool inserts. The data was compiled into MINITAB ${ }^{\circledR} 17$ for analysis. Design of Experiments (DOE) was conducted to analyze the impact of cutting parameters on the Material Removal Rate (MRR) and Surface Roughness (SR) by using Taguchi method. By conducting Analysis of Variance (ANOVA) the results are optimized to determine minimum surface roughness and maximum MRR. Response Surface Optimizer was used for obtaining optimum settings to carry out the machining operations effectively.
\end{abstract}

Index Terms: turning, cutting tool inserts, material removal rate, surface roughness, and optimization

\section{INTRODUCTION}

Turning is the basic machining operation in which the excess material from the rotated work-piece is removed in the form of chips, by moving a single point cutting tool parallel to the axis of rotation of work-piece, to get exact size and shape of the work-piece. Turning can be done on both the external surface and internal surface of the work part.

To achieve high process performance of turning, it is necessary to choose suitable parameters.

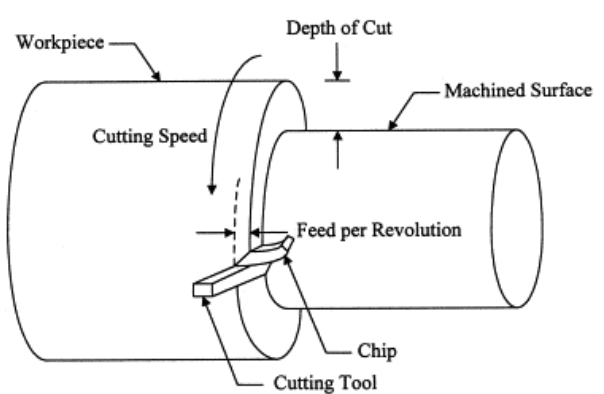

Figure 1. Schematic diagram of turning operation

\section{LITERATURE SURVEY}

Singh and Kumar [1] investigated feed force optimization through turning operation of EN24 work piece material by using coated tungsten carbide inserts, varying process parameters.

Ali Riza Motorcu [2] studied the impact of surface roughness during turning of AISI 8660 steel, where the cutting tool used was P.V.D coated ceramic. The results revealed that the feed and depth of cut are more significant parameters.

Adarsh kumar et al. [3] analyzed the effect of surface roughness on EN-8 steel by altering the cutting parameters. The ultimate aim is to correlate and optimize the cutting parameters using multiple regression analysis.

Yong et al. [4] stated that there was excellent increase in life of tool after normal (28.9\%), deep (38.6\%) treatment of milling inserts treated cryogenically made up of tungsten carbide.

Stewart [5] implemented cryogenically cured C2 WC Co inserts to make out tool wear before and after turning operation of the work piece made of medium density fibre (MDF). The results revealed less tool wear with cryogenically treated tools in comparison to untreated one. He suggested that the cryogenic treatment might have an influence upon the cobalt binder by changing its crystallographic phase.

A lot of work has been done in improving material removal rate and surface modification with Turning Operation. From the literature survey, it is observed that many researchers used High Speed Steels, AISI Steels and composite materials with Carbide and CBN Cutting Tools and examined the various output responses like surface roughness, tool wear rate, material removal rate.

More research is required in field of turning process as there is lackage of few concepts. From the literature review, it is observed that no research work has been carried out on improvement of material removal rate and surface Roughness using Aluminium, normalised steel and Stainless 
steel 316. No work has been reported on Carbide and Titanium cutting inserts. All these aspects will be addressed in the research work

\section{OBJECTIVE OF THE PROJECT}

To analyze the influence of cutting parameters on the material removal rate and surface roughness while turning of Aluminium, Normalised Steel and Stainless steel-316 by using Carbide and Titanium Cutting inserts.

$>$ To make a comparison between the effects of cutting parameters with different materials (Aluminium, Normalised steel and Stainless steel 316) by using cutting tool inserts (Carbide and Titanium)

$>$ To determine the optimal settings for the work-tool combinations.

\section{EXPERIMENTAL DESIGN}

The aim of this research work is to study the influence of cutting parameters on the Material Removal Rate and surface roughness during turning operation of various work materials, using Carbide and Titanium Cutting tool inserts. The designed process variables can be summarized as follows:

Two types of cutting tool inserts

$>$ Three levels of speed.

$>$ Three levels of feed rate.

$>$ Three levels of depth of cut.

$>$ Three types of work piece materials.

To carry out the Taguchi method of experimental design and an appropriate orthogonal array is to be selected after taking into consideration of the above designed process variables [6]. The influence of each cutting parameter on the concept of surface modification should be studied in order to know its behavior [7]. Thus, it was decided to conduct experiments with each combination of cutting parameters. Out of the above listed designed process variables, the orthogonal array is selected for five design variables which would represent the orthogonal array.

Based on the number of parameters and the levels, an orthogonal array is confirmed by using the array selector.

TABLE I.

ARRAY SELECTOR

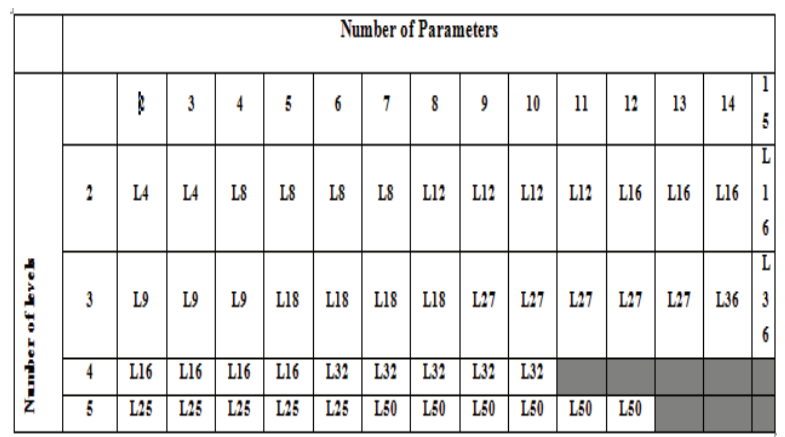

The arrays are generated using Taguchi algorithm; it allows testing of each parameter and settings, equally. MINITAB 17 which is a statistical software was used to assign factors for the present work.

TABLE II.

MACHINING PARAMETERS AND THEIR LEVELS

\begin{tabular}{|c|c|c|c|}
\hline \multirow{2}{*}{ Parameters } & \multicolumn{3}{|c|}{ Levels } \\
\cline { 2 - 4 } & $\mathbf{1}$ & $\mathbf{2}$ & $\mathbf{3}$ \\
\hline Inserts & Carbide & Titanium & -- \\
\hline Speed & 280 & 450 & 710 \\
\hline Feed & 0.2 & 0.4 & 0.63 \\
\hline $\begin{array}{c}\text { Depth of } \\
\text { cut }\end{array}$ & 0.5 & 1.0 & 1.5 \\
\hline \begin{tabular}{c} 
Work piece \\
\hline
\end{tabular} & $\mathrm{SS} 316$ & $\begin{array}{c}\text { Normalised } \\
\text { steel }\end{array}$ & Aluminium \\
\hline
\end{tabular}

TABLE III.

STANDARD L18 ORTHOGONAL ARRAY (TAGUCHI DESIGN)

\begin{tabular}{|c|c|c|c|c|c|}
\hline $\begin{array}{l}\text { Exp } \\
\text { No. }\end{array}$ & $\begin{array}{c}\text { Parameter } \\
1 \\
\end{array}$ & $\begin{array}{c}\text { Parameter } \\
2 \\
\end{array}$ & $\begin{array}{c}\text { Parameter } \\
3 \\
\end{array}$ & $\begin{array}{c}\text { Parameter } \\
4 \\
\end{array}$ & $\begin{array}{c}\text { Parameter } \\
5 \\
\end{array}$ \\
\hline 1 & 1 & 1 & 1 & 1 & 1 \\
\hline 2 & 1 & 1 & 2 & 2 & 2 \\
\hline 3 & 1 & 1 & 3 & 3 & 3 \\
\hline 4 & 1 & 2 & 1 & 1 & 2 \\
\hline 5 & 1 & 2 & 2 & 2 & 3 \\
\hline 6 & 1 & 2 & 3 & 3 & 1 \\
\hline 7 & 1 & 3 & 1 & 2 & 1 \\
\hline 8 & 1 & 3 & 2 & 3 & 2 \\
\hline 9 & 1 & 3 & 3 & 1 & 3 \\
\hline 10 & 2 & 1 & 1 & 3 & 3 \\
\hline 11 & 2 & 1 & 2 & 1 & 1 \\
\hline 12 & 2 & 1 & 3 & 2 & 2 \\
\hline 13 & 2 & 2 & 1 & 2 & 3 \\
\hline 14 & 2 & 2 & 2 & 3 & 1 \\
\hline 15 & 2 & 2 & 3 & 1 & 2 \\
\hline 16 & 2 & 3 & 1 & 3 & 2 \\
\hline 17 & 2 & 3 & 2 & 1 & 3 \\
\hline 18 & 2 & 3 & 3 & 2 & 1 \\
\hline
\end{tabular}


TABLE IV.

EXPERIMENTAL SETTING For L18 ORTHOGONAL ARRAY (TAGUCHI DESIGN)

\begin{tabular}{|l|l|l|c|c|l|}
\hline $\begin{array}{c}\text { Exp } \\
\text { No. }\end{array}$ & Inserts & $\begin{array}{c}\text { Speed } \\
(\mathbf{r p m})\end{array}$ & $\begin{array}{c}\text { Feed } \\
(\mathbf{m m} / \text { rev })\end{array}$ & $\begin{array}{c}\text { depth } \\
\text { of cut } \\
(\mathbf{m m})\end{array}$ & Work piece \\
\hline 1 & Carbide & 280 & 0.2 & 0.5 & SS 316 \\
\hline
\end{tabular}

Figure 2. Carbide insert

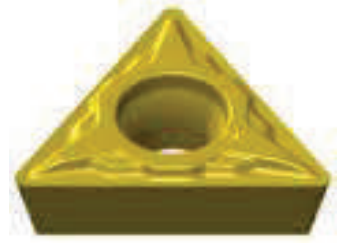

Figure 3. Titanium insert
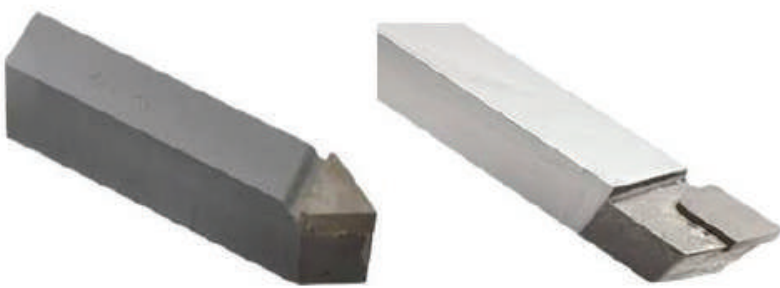

Figure 4. HSS cutting tool with carbide and Titanium Insert

\section{B. Equipments used for experiment:}

Jobber XL CNC horizontal lathe machine was used to perform exepriments for the present work.

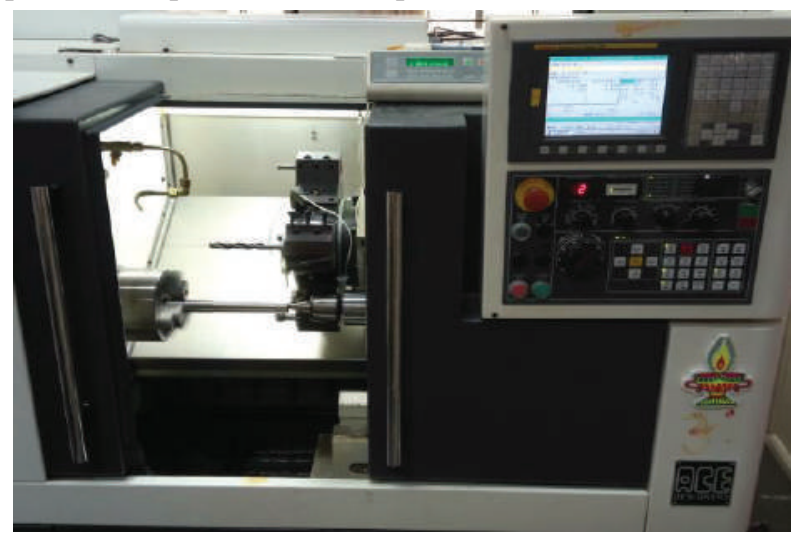

Figure 5. Jobber XL CNC lathe (CVR College)

Taly surf was used for measuring surface roughness of work materials

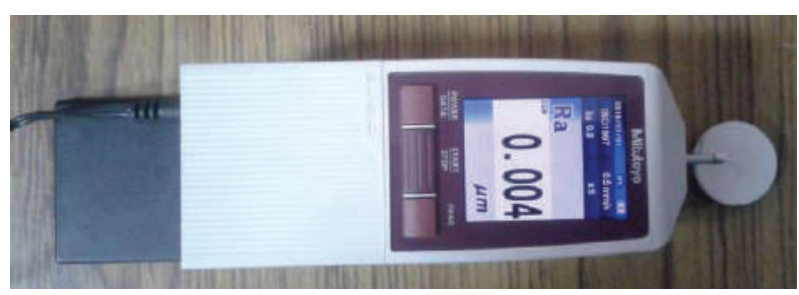

Figure 6. Talysurf (CVR College) 


\section{RESULTS AND ANALYSIS}

A. Results of material removal rate and Surface Roughness:

The results for rate of material removed were summarized as shown in table 4. The diameter of the work piece before and after machining is determined to evaluate the MRR of each trail. The MRR is given by

\section{$M R R=1000 \mathrm{Vfa}$}

Where, $\mathrm{V}=\pi \mathrm{dn} / 1000$, is cutting speed in $\mathrm{m} / \mathrm{min}$ $\mathrm{d}$ is the average diameter of the work piece in $\mathrm{mm}$ $\mathrm{n}$ is the spindle speed in rpm

$\mathrm{f}$ is feed in $\mathrm{mm} / \mathrm{rev}$ $\mathrm{a}$ is depth of cut in $\mathrm{mm}$.
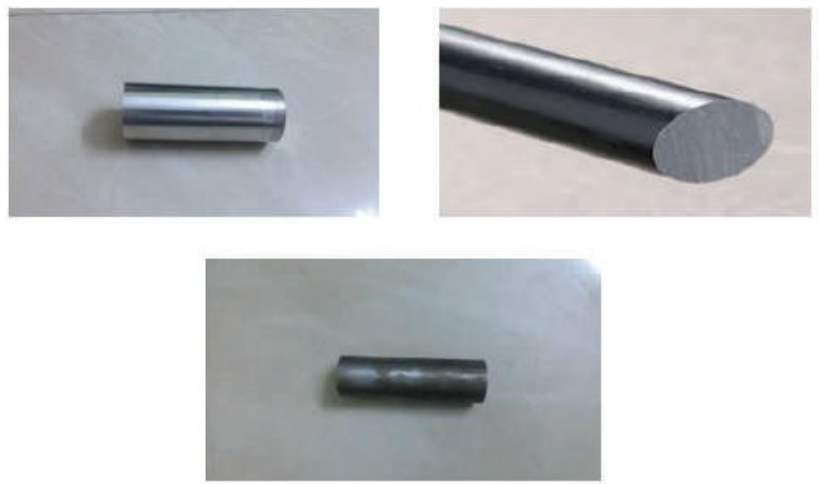

Figure 7. Work pieces before machining
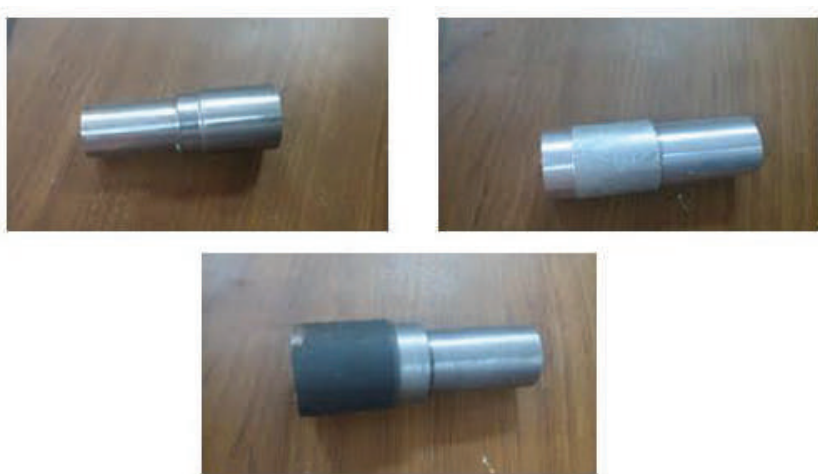

Figure 8 . Work pieces after machining

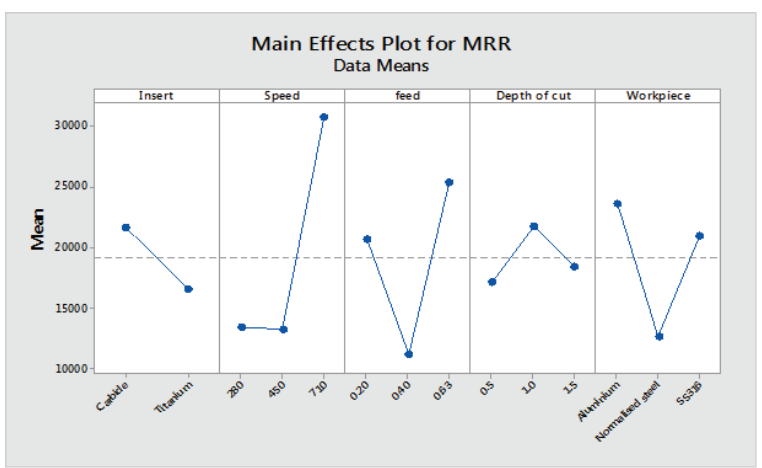

Figure 9. Main effects plot for Material Removal Rate

Fig 9 shows that the Mean material removal rate is higher in case of Carbide insert compared to the Titanium insert. This is perhaps due to the hardness of the insert, high thermal conductivity and higher toughness. As the speed increases the mean of material removal rate decreases first upto some value and then increases. As the feed increases the mean of material removal rate decreases first upto some value and then increases. It is clear that as the depth of cut increases the mean of material removal rate increases first up to some value and then decreases. Among all the the work pieces the maximum mean MRR is for Aluminium.

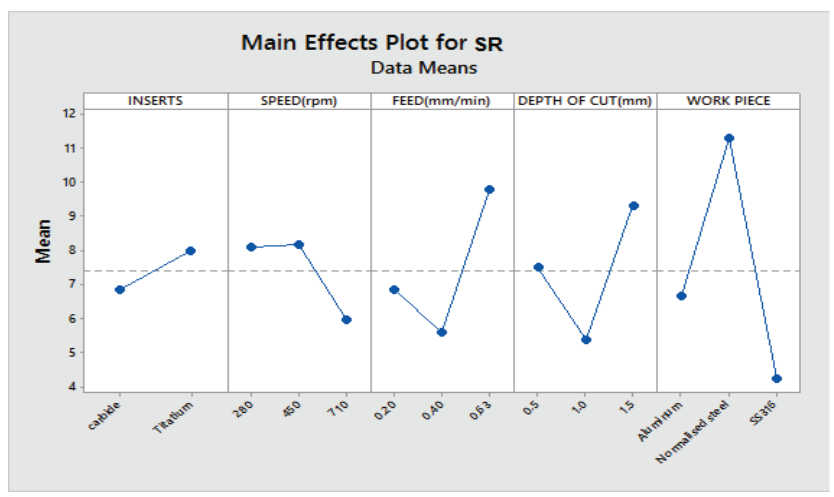

Figure 10. Main effects plot for Surface Roughness

Fig. 10 depicts that the carbide tool insert produces minimum surface roughness as compared to titanium inserts. As the speed increases the surface roughness increases to extent and beyond it decreases. As the feed and depth of cut increases the surface roughness varies similarly. Among all work pieces stainless steel-316 is shows superior surface finish. 
TABLE VI.

RESUlts For MATERIAL REMOVAL RATE AND SURFACE RoughNESS

\begin{tabular}{|c|c|c|c|c|c|c|c|}
\hline Exp.No & Inserts & $\begin{array}{l}\text { Speed } \\
\text { (rpm) }\end{array}$ & $\begin{array}{c}\text { Feed } \\
(\mathrm{mm} / \mathrm{rev})\end{array}$ & $\begin{array}{c}\text { Depth of cut } \\
(\mathrm{mm})\end{array}$ & Work piece & $\begin{array}{c}\text { MRR } \\
\left(\mathrm{mm}^{3} / \mathrm{min}\right)\end{array}$ & $\begin{array}{c}\text { SR } \\
\text { (Microns) }\end{array}$ \\
\hline 1 & Carbide & 280 & 0.2 & 0.5 & SS316 & 3140.3 & 4.5585 \\
\hline 2 & Carbide & 280 & 0.4 & 1.0 & Normalised steel & 12491.0 & 7.152 \\
\hline 3 & Carbide & 280 & 0.63 & 1.5 & Aluminium & 29925.1 & 20.067 \\
\hline 4 & Carbide & 450 & 0.2 & 0.5 & Normalised steel & 18837.1 & 11.3293 \\
\hline 5 & Carbide & 450 & 0.4 & 1.0 & Aluminium & 4895.0 & 1.4726 \\
\hline 6 & Carbide & 450 & 0.63 & 1.5 & SS316 & 19226.5 & 2.608 \\
\hline 7 & Carbide & 710 & 0.2 & 1.0 & SS316 & 46424.7 & 2.615 \\
\hline 8 & Carbide & 710 & 0.4 & 1.5 & Normalised steel & 14944.5 & 7.7156 \\
\hline 9 & Carbide & 710 & 0.63 & 0.5 & Aluminium & 45168.2 & 3.8616 \\
\hline 10 & Titanium & 280 & 0.2 & 1.5 & Aluminium & 23362.0 & 2.996 \\
\hline 11 & Titanium & 280 & 0.4 & 0.5 & $\mathrm{SS} 316$ & 5673.7 & 2.761 \\
\hline 12 & Titanium & 280 & 0.63 & 1.0 & Normalised steel & 5761.7 & 10.977 \\
\hline 13 & Titanium & 450 & 0.2 & 1.0 & Aluminium & 18010.8 & 6.565 \\
\hline 14 & Titanium & 450 & 0.4 & 1.5 & SS316 & 8765.0 & 9.4383 \\
\hline 15 & Titanium & 450 & 0.63 & 0.5 & Normalised steel & 9426.0 & 17.523 \\
\hline 16 & Titanium & 710 & 0.2 & 1.5 & Normalised steel & 14361.6 & 13.0116 \\
\hline 17 & Titanium & 710 & 0.4 & 0.5 & Aluminium & 20576.6 & 4.963 \\
\hline 18 & Titanium & 710 & 0.63 & 1 & SS316 & 42859.5 & 3.5116 \\
\hline
\end{tabular}

B. ANOVA for MRR:

TABLE VII.

ANOVA For MATERIAL REMOVAL RATE

\begin{tabular}{|l|l|l|l|l|l|}
\hline \multicolumn{1}{|c|}{ Source } & DF & Adj SS & Adj MS & $\begin{array}{l}\text { F- } \\
\text { Value }\end{array}$ & $\begin{array}{l}\text { P- } \\
\text { Value }\end{array}$ \\
\hline $\begin{array}{l}\text { Speed } \\
\text { (rpm) }\end{array}$ & 2 & 1215291804 & 607645902 & 6.05 & 0.025 \\
\hline Inserts & 1 & 118865441 & 118865441 & 1.18 & 0.308 \\
\hline Feed & 2 & 625041621 & 312520811 & 3.11 & 0.100 \\
\hline $\begin{array}{l}\text { Depth of } \\
\text { cut }\end{array}$ & 2 & 67639434 & 33819717 & 0.34 & 0.724 \\
\hline Work piece & 2 & 397183879 & 198591940 & 1.98 & 0.201 \\
\hline Error & 8 & 803949257 & 1000493657 & & \\
\hline Total & 17 & 3227971068 & & & \\
\hline
\end{tabular}

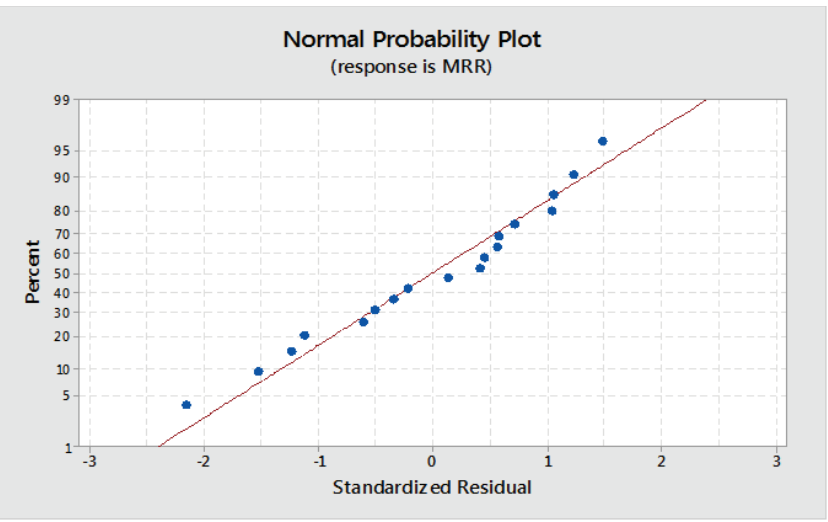

Figure 11. Normal plot of Residual for Material Removal Rate

Fig. 11 depicts that most of the points are nearer to a straight line, which reveals that the errors are normally distributed. Therefore model is satisfactory. 


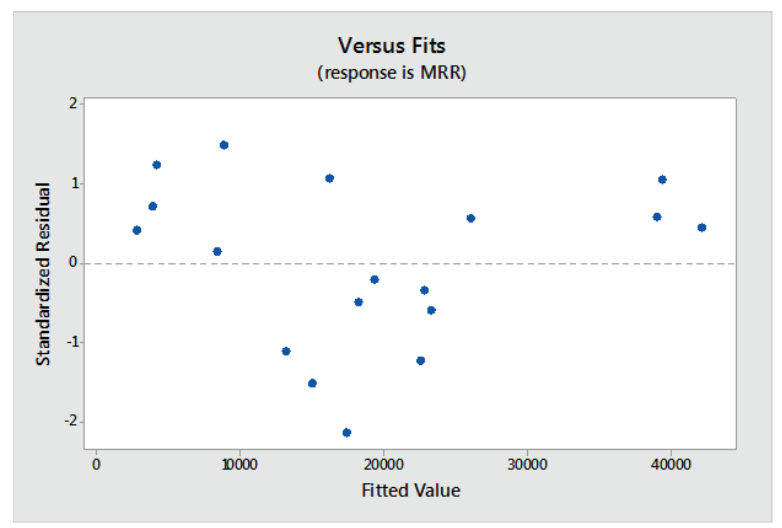

Figure12. Residual vs Fit for Material Removal Rate

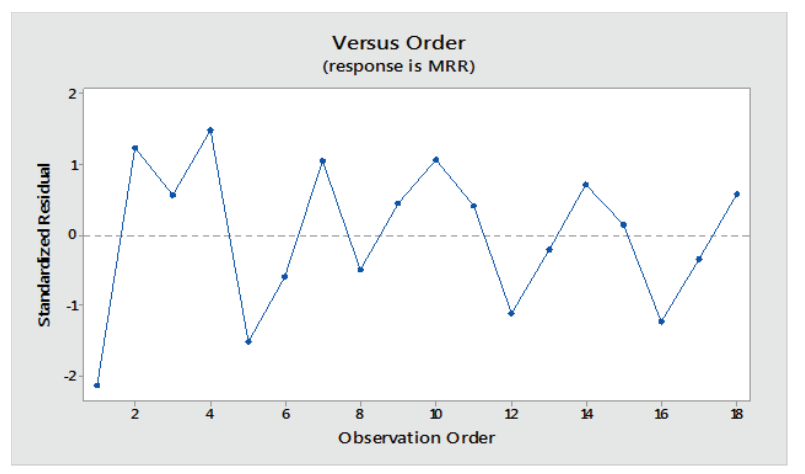

Figure 13. Residual vs Order for Material Removal Rate

Fig. 12 and 13 predicts that the response doesn't have regular structural pattern.

\section{ANOVA for Surface Roughness}

TABLE VIII.

ANOVA For SURFACE ROUGHNESS

\begin{tabular}{|c|c|c|c|c|c|}
\hline Source & DF & Adj SS & $\begin{array}{c}\text { Adj } \\
\text { MS }\end{array}$ & $\begin{array}{c}\text { F- } \\
\text { Value }\end{array}$ & $\begin{array}{c}\text { P- } \\
\text { Value }\end{array}$ \\
\hline Speed (rpm) & 2 & 18.924 & 9.462 & 0.36 & 0.710 \\
\hline Inserts & 1 & 5.971 & 5.971 & 0.23 & 0.647 \\
\hline $\begin{array}{c}\text { Feed } \\
\text { (mm/rev) }\end{array}$ & 2 & 54.996 & 27.498 & 1.04 & 0.396 \\
\hline $\begin{array}{c}\text { Depth of cut } \\
(\mathrm{mm})\end{array}$ & 2 & 46.287 & 23.144 & 0.88 & 0.0453 \\
\hline Work piece & 2 & 153.468 & 76.734 & 2.90 & 0.113 \\
\hline Error & 8 & 211.581 & 26.448 & - & - \\
\hline Total & 17 & 491.227 & - & - & - \\
\hline
\end{tabular}

The ANOVA results for SR reveals that, as P-value for depth of cut is less than standard value (0.05). It concludes that speed is the most significant parameter as compared with other parameters.

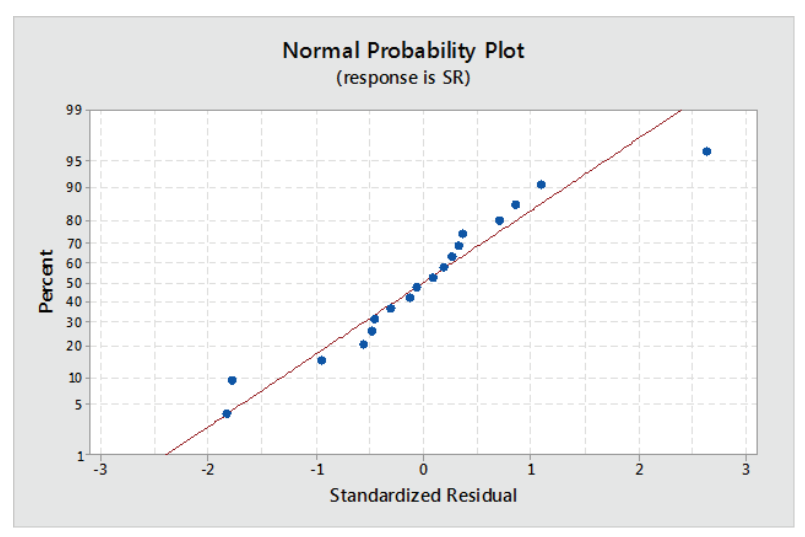

Figure 14. Normal Plot of Residual for Surface Roughness

Fig. 14 depicts that most of the points are nearer to a straight line, which reveals that the errors are normally distributed. Therefore model is satisfactory.

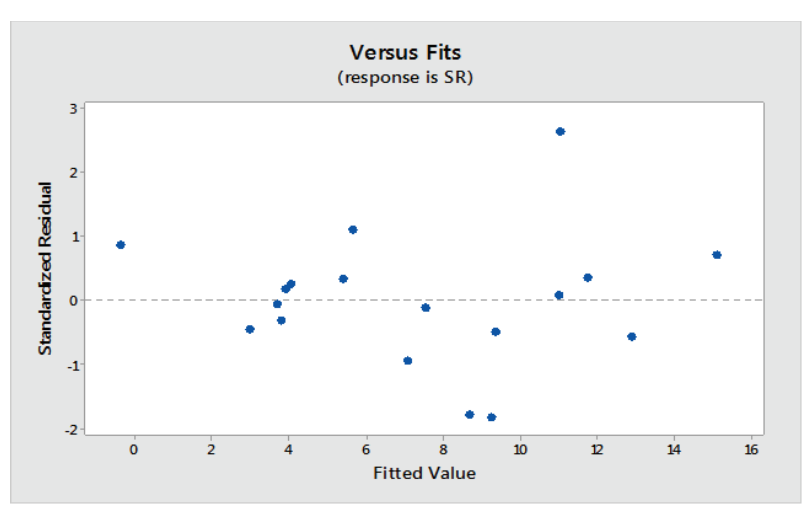

Figure 15. Residual vs Fit for Surface Roughness

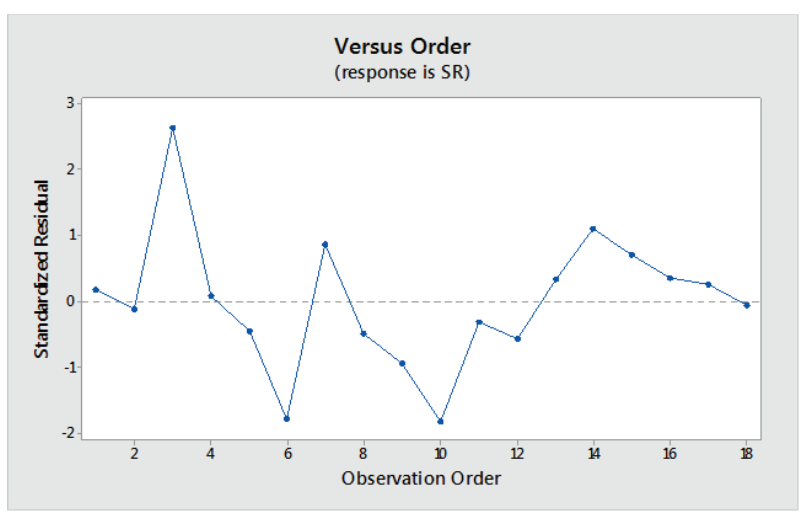

Figure 16. Residual vs order for Surface Roughness

Fig. 15 and 16 predicts that the response doesn't have regular structural pattern. 


\section{E. Optimum settings:}

The three finest optimum settings shown below are:

TABLE IX.

TOP THREE OPTIMUM SETTINGS

\begin{tabular}{|c|c|c|c|c|c|}
\hline $\begin{array}{l}\text { Exp } \\
\text { No }\end{array}$ & Inserts & $\begin{array}{c}\text { Speed } \\
(\mathbf{r p m})\end{array}$ & $\begin{array}{c}\text { Feed } \\
(\mathbf{m m} / \mathbf{r e v})\end{array}$ & $\begin{array}{c}\text { Depth of } \\
\text { cut (mm) }\end{array}$ & $\begin{array}{c}\text { Work } \\
\text { piece }\end{array}$ \\
\hline 1 & Titanium & 710 & 0.63 & 1.5 & $\mathrm{SS} 316$ \\
\hline 2 & Carbide & 710 & 0.63 & 1 & $\mathrm{SS} 316$ \\
\hline 3 & Carbide & 280 & 0.2 & 0.5 & Aluminum \\
\hline
\end{tabular}

The optimization plot depicts that, how the required response (surface roughness and Material Removal Rate) alters with the increased speed, feed rate and depth of cut). The optimal setting is assessed by maximum desirability.

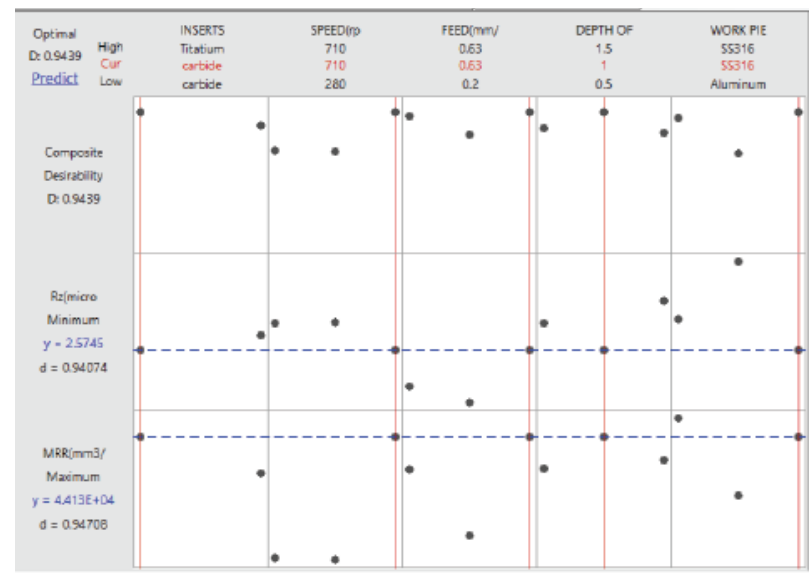

Figure 17. Optimization Plot

\section{CONCLuSions}

1) From the above experiments, it is concluded that the higher material removal rate and lower Surface roughness is possible with the optimum parameters.

2) By determining optimum settings for the machining operation, it is possible to reduce the machining time thereby increasing the productivity.

3) The MRR was maximum for carbide tool insert when compared to the titanium tool insert.

4) The SR was minimum for carbide tool insert when compared to the titanium tool insert.

5) The above results imply that speed has the largest influence on MRR followed by other cutting parameters.

6) The above results imply that depth of cut has the largest influence on SR followed by other cutting parameters.

\section{REFERENCES}

[1] Singh H. and Kumar P., "Optimizing Feed Force for Turned Parts through the Taguchi Technique", Sadhana, Volume 31, Number 6, pp. 671-681. (2006).

[2] Ali Riza Motorcu " The optimisation of machining parameters using the Taguchi method for surface roughness of AISI 8660 hardened alloy steel" Journal of mechanical Engineering 566, 391-401, (2010).

[3] Adarsh kumar et.al, "Optimization Of Surface Roughness In Face Turning Operation In Machining Of EN-8" International Journal Of Engineering Science \& Advanced Technology Volume-2, Issue-4, $807-812$

[4] Yong A, Seah K, Rahman M. Performance of cryogenically treated tungsten car-bide tools in milling operations. Int J Adv Manuf Technol, 32 (7-8):638-43, 2007.

[5] Stewart HA. Cryogenic treatment of tungsten carbide reduces tool wear whenmachining medium density fiberboard. For Prod J;54 (2):53, 2004.

[6] Design of Experiments Using the Taguchi Approach: 16 Steps to Product and Process Improvement by Ranjith K. Roy.

[7] Taguchi`s quality engineering hand book by Subir Chowdhury. 